\title{
Differential Maturation of GABA Action and Anion Reversal Potential in Spinal Lamina I Neurons: Impact of Chloride Extrusion Capacity
}

\author{
Matilde Cordero-Erausquin, ${ }^{1}$ Jeffrey A. M. Coull, ${ }^{1,2}$ Dominic Boudreau, ${ }^{1}$ Matthias Rolland, ${ }^{1}$ and Yves De Koninck ${ }^{1,2}$ \\ ${ }^{1}$ Division de Neurobiologie Cellulaire, Centre de Recherche Université Laval Robert-Giffard, Québec, Québec, Canada G1J 2G3, and ²Department of \\ Pharmacology and Therapeutics, McGill University, Montreal, Québec, Canada H3A 1 Y6
}

\begin{abstract}
A deficit in inhibition in the spinal dorsal horn has been proposed to be an underlying cause of the exaggerated cutaneous sensory reflexes observed in newborn rats. However, the developmental shift in transmembrane anion gradient, potentially affecting the outcome of $\mathrm{GABA}_{\mathrm{A}}$ transmission, was shown to be completed within 1 week after birth in the spinal cord, an apparent disparity with the observation that reflex hypersensitivity persists throughout the first 2-3 postnatal weeks.

To further investigate this issue, we used several approaches to assess the action of GABA throughout development in spinal lamina I (LI) neurons. GABA induced an entry of extracellular calcium in LI neurons from postnatal day $0(\mathrm{P} 0)$ to $\mathrm{P} 21$ rats, which involved T- and $\mathrm{N}$-type voltage-gated calcium channels. Gramicidin perforated-patch recordings revealed that the shift in anion gradient was completed by P7 in LI neurons. However, high chloride pipette recordings demonstrated that these neurons had not reached their adult chloride extrusion capacity by P10-P11. Simultaneous patch-clamp recordings and calcium imaging revealed that biphasic responses to GABA, consisting of a primary hyperpolarization followed by a rebound depolarization, produced a rise in $\left[\mathrm{Ca}^{2+}\right]_{\mathrm{i}}$. Thus, even if $E_{\text {anion }}$ predicts $\mathrm{GABA}_{\mathrm{A}}$-induced hyperpolarization from rest, a low chloride extrusion capacity can cause a rebound depolarization and an ensuing rise in $\left[\mathrm{Ca}^{2+}\right]_{\mathrm{i}}$.

We demonstrate that GABA action in LI neurons matures throughout the first 3 postnatal weeks, therefore matching the time course of maturation of withdrawal reflexes. Immature spinal GABA signaling may thus contribute to the nociceptive hypersensitivity in infant rats.
\end{abstract}

Key words: development; dorsal horn; nociception; pain; inhibition; perforated patch-clamp; calcium channels; chloride; anion transport

\section{Introduction}

Reports on cutaneous sensory responses in newborn rats reveal striking differences with those of adults. The threshold for nociceptive withdrawal reflexes is low in neonates and increases with age, reaching adult values between postnatal day 12 (P12) and P20 (Falcon et al., 1996; Jiang and Gebhart, 1998; Teng and Abbott, 1998; Marsh et al., 1999). Electromyographic measurements similarly reveal lower nociceptive threshold as well as prolonged responses in newborns compared with adults (Fitzgerald and Gibson, 1984; Jiang and Gebhart, 1998). Altogether, these reports indicate exaggerated sensory responses in young animals compared with adults.

Because cutaneous primary afferent properties at birth are similar to those in adults, it has been suggested that central rather than peripheral mechanisms are responsible for the postnatal

Received Dec. 12, 2004; revised Sept. 5, 2005; accepted Sept. 6, 2005.

This work was supported by Canadian Institutes of Health Research Grant MT-12942 (Y.D.K.). Y.D.K. is a Senior Scholar of the Fonds de la Recherche en Santé du Québec (FRSQ). M.C.-E. is the recipient of a postdoctoral fellowship from the FRSQ. We thank Dr. C. Labrakakis for helpful discussions and comments on this manuscript.

Correspondence should be addressed to Yves De Koninck, Division de Neurobiologie Cellulaire, Centre de Recherche Université Laval Robert-Giffard, 2601, Chemin de la Canardière, Québec, Québec, Canada G1J 2G3. E-mail: yves.dekoninck@crulrg.ulaval.ca.

DOl:10.1523/JNEUROSCI.1488-05.2005

Copyright $\odot 2005$ Society for Neuroscience $\quad$ 0270-6474/05/259613-11\$15.00/0 changes in cutaneous sensory reflexes (Fitzgerald, 1987). The first site within the CNS in which input from sensory fibers is integrated is the dorsal horn of the spinal cord. Single-unit recordings in vivo reveal that neonate dorsal horn neurons have prolonged afterdischarges to both innocuous and noxious stimulation and possess large receptive fields, in sharp contrast with the adult phenotype, which is progressively reached by the end of the second postnatal week (Fitzgerald, 1985). These features of immature dorsal horn neurons are typical of what is observed as a result of disinhibition in the adult spinal cord (Game and Lodge, 1975; Sorkin et al., 1998; Schwark et al., 1999), and thus the question has been raised whether a deficit in spinal inhibition accounts for the exaggerated responses observed in young animals (Fitzgerald, 1985; Baccei and Fitzgerald, 2004).

The principal inhibitory neurotransmitters GABA and glycine have been shown in many regions of the CNS to be depolarizing in neonates (for review, see Ben Ari et al., 1997), therefore providing a possible explanation for a deficit in inhibition. This depolarization results from the fact that the reversal potential for $\mathrm{GABA}_{\mathrm{A}}$ and glycine receptor-mediated currents is more positive than the resting membrane potential in immature neurons (Kaila, 1994; Ben Ari et al., 1997). This has also been shown in the dorsal horn, in which $40 \%$ of neurons at P0-P1 are depolarized by GABA (Baccei and Fitzgerald, 2004). This depolarization does 
not appear to reach threshold for action potentials, and, from P6 onward, all neurons are hyperpolarized by GABA. It has therefore been questioned whether GABA-induced depolarization can account for the proposed greater excitability in the dorsal horn during the first 2-3 postnatal weeks (Baccei and Fitzgerald, 2004). Suprathreshold responses to GABA are however not the only mechanism by which the excitability of the network could be raised. For example, a net change in the input/output curve of dorsal horn neurons can occur with a slight depolarizing shift in the anion reversal potential ( $\left.E_{\text {anion }}\right)$ (Coull et al., 2003).

To further investigate this issue, we used several approaches to assess the action of GABA throughout development in spinal dorsal horn neurons. We focused on lamina I (LI) because this layer constitutes one of the main output pathways for the relay of nociceptive information to the brain [e.g., $\sim 50 \%$ of the spinothalamic tract (Lima and Coimbra, 1988)]. We evaluated the characteristics of $\mathrm{GABA}_{\mathrm{A}}$ receptor-mediated responses through monitoring of intracellular calcium $\left(\left[\mathrm{Ca}^{2+}\right]_{\mathrm{i}}\right)$, perforated and whole-cell patch-clamp recordings, and measurement of $\mathrm{Cl}^{-}$extrusion capacity in spinal slices obtained from rats at different stages of postnatal development. Using this comprehensive approach, we demonstrate that, when diverse aspects of GABA function are considered, $\mathrm{GABA}_{\mathrm{A}}$ receptor-mediated transmission does indeed reach its adult phenotype only by the end of the third postnatal week, which is the time when young rats reach their adult phenotype for nociceptive withdrawal reflexes.

\section{Materials and Methods}

All experimental procedures have been performed in accordance with guidelines from the Canadian Council on Animal Care.

Preparation of spinal cord slices. Male Sprague Dawley rats (Charles River Laboratories, Wilmington, MA), aged P0-P60, were anesthetized by hypothermia (P0-P2) or with ketamine/xylazine (older than P2) and decapitated. The spinal cord was rapidly removed by hydraulic extrusion and immersed in an ice-cold oxygenated $\left(95 \% \mathrm{O}_{2}, 5 \% \mathrm{CO}_{2}\right)$ artificial CSF (ACSF) solution containing the following (in $\mathrm{mm}$ ): 252 sucrose, $2.5 \mathrm{KCl}$, $2 \mathrm{MgCl}_{2}, 2 \mathrm{CaCl}_{2}, 1.25 \mathrm{NaHPO}_{4}, 26 \mathrm{NaHCO}_{3}, 10$ glucose, and 5 kynurenate. Rats older than P14 were briefly perfused transcardially with this solution before decapitation. The lumbar spinal enlargement was isolated, 250-300 $\mu \mathrm{m}$ slices were cut in the parasagittal plane using a Leica (Nussloch, Germany) vibratome, and slices were allowed to recover for 15-30 min in an immersion chamber.

Calcium imaging. The spinal slices were loaded for $1 \mathrm{~h}$ with $10 \mu \mathrm{M}$ fura-2 AM [1-10\% DMSO in a HEPES-buffered solution composed of the following (in mM): $10 \mathrm{HEPES}, 126 \mathrm{NaCl}, 2.5 \mathrm{KCl}, 2 \mathrm{MgCl}_{2}, 2 \mathrm{CaCl}_{2}$, and 23 glucose]. Slices were then transferred to an oxygenated ACSF composed of the following (in $\mathrm{mm}$ ): $126 \mathrm{NaCl}, 2.5 \mathrm{KCl}, 2 \mathrm{MgCl}_{2}, 2 \mathrm{CaCl}_{2}$, $1.25 \mathrm{NaHPO}_{4}$, and $26 \mathrm{NaHCO}_{3}$.

Intracellular $\left[\mathrm{Ca}^{2+}\right]$ was measured fluorometrically using a Zeiss (Oberkochen, Germany) Axioscope equipped with epifluorescence optics and a T.I.L.L. Photonics (Martinsried, Germany) monochromator. Regions of interest (for ratioing) were drawn on clearly distinct neuronal cell bodies. Paired images ( 340 and $380 \mathrm{~nm}$ excitation, $510 \mathrm{~nm}$ emission) were collected every 56 to $250 \mathrm{~ms}$, and pseudocolor ratiometric images were monitored during the experiments. Peak ratio responses are expressed as percentage of the baseline ratio.

Electrophysiology. After $1 \mathrm{~h}$ of recovery in oxygenated ACSF, individual slices were transferred to a recording chamber and continuously superfused with oxygenated ACSF. For bicarbonate-free recordings, the slices were superfused by the abovementioned HEPES-buffered ACSF (oxygenated with $\left.100 \% \mathrm{O}_{2}\right)$. Patch pipettes $(7-8 \mathrm{M} \Omega$ ) were pulled on a two-stage vertical puller (PP-83; Narishige, Tokyo, Japan) and filled with the following (in mM): $140 \mathrm{~K}$-methylsulfate, $2 \mathrm{MgCl}_{2}, 5 \mathrm{KCl}$, and 10 HEPES, pH 7.2 adjusted with $\mathrm{KOH}$. This solution was complemented by $25 \mu \mathrm{g} / \mathrm{ml}$ gramicidin (Abe et al., 1994; Kyrozis and Reichling, 1995) and
0.5\% Lucifer yellow for perforated-patch experiments or $120 \mathrm{~mm}$ fura-2 and $0.2 \%$ Neurobiotin, for simultaneous whole-cell patch-clamp and calcium imaging.

For high pipette $\left[\mathrm{Cl}^{-}\right]$recordings, K-methylsulfate was replaced with $\mathrm{KCl}$ to obtain the desired pipette $\left[\mathrm{Cl}^{-}\right]$. Because the purity of chloride salts may vary between sources (DeFazio et al., 2000), the pipette $\left[\mathrm{Cl}^{-}\right]$ was confirmed through $E_{\text {anion }}$ measurements from excised patch recordings. To inhibit potassium conductances, we also performed a series of recordings with a cesium-based pipette solution containing the following (in mM): 130 Cs-methanesulfonate, $5 \mathrm{CsCl}, 2 \mathrm{MgCl}_{2}, 0.5$ EGTA, 2 TrisATP, 0.4 GTP, and 10 HEPES, pH 7.2 adjusted with $\mathrm{CsOH}$.

Perforated-patch, whole-cell and excised patch recordings were made using an Axopatch-200B amplifier (Axon Instruments, Union City, CA), operating under current-clamp and voltage-clamp mode. Data were filtered at $0.5-5 \mathrm{kHz}$, digitized at $1-16 \mathrm{kHz}$, and acquired using the Strathclyde electrophysiology software WinWCP (courtesy of Dr. J. Dempster, University of Strathclyde, Glasgow, UK).

Monosynaptic IPSCs were evoked by electrical stimulation $(50 \mu \mathrm{A}$, $100 \mu \mathrm{s}$ ) delivered focally via a patch micropipette placed in the vicinity of the recorded cell as described previously (Chery and De Koninck, 1999). Trains of stimuli (5-20 pulses of $100 \mu$ s duration each; 10-50 ms apart; i.e., $20-100 \mathrm{~Hz}$ intraburst frequency) were delivered every $10 \mathrm{~s}$.

Drug applications. Exogenous GABA (1 mM) and muscimol (100 $\mu \mathrm{M})$ (or 100-500 $\mathrm{mm} \mathrm{KCl),} \mathrm{dissolved} \mathrm{into} \mathrm{a} \mathrm{HEPES-buffered} \mathrm{solution,} \mathrm{were}$ applied locally for 20-30 ms (unless otherwise specified) by pressure ejection from a patch micropipette. Other drugs were bath applied as follows: bicuculline methiodide ( $25 \mu \mathrm{M}$; Research Biochemicals, Natick, MA) for selective blockade of $\mathrm{GABA}_{\mathrm{A}}$ receptors; tetrodotoxin (TTX) (1 $\mu \mathrm{M}$; Tocris Cookson, Ballwin, $\mathrm{MO}$ ) to block action potential generation and thus network activity; 6-cyano-7-nitroquinoxaline-2,3-dione (CNQX) (10 $\mu \mathrm{M}$; Sigma, St. Louis, MO) or 6,7-dinitroquinoxaline-2,3dione (DNQX) (10 $\mu \mathrm{M}$; Sigma) and $\mathrm{D}(-)$-2-amino-5-phosphonopentanoic acid (D-AP-5) (40 $\mu \mathrm{M}$; Sigma) to block fast glutamatergic transmission and focus on direct postsynaptic action of GABA as well as to isolate stimulus-evoked monosynaptic IPSCs; CGP 52432 (3[[(3,4-dichlorophenyl)-methyl] amino]propyl](diethoxymethyl)phosphinic acid) (30 $\mu$ m; Tocris Cookson) to block $\mathrm{GABA}_{\mathrm{B}}$ receptors; and furosemide ( $250 \mu \mathrm{M}$; Sigma) to block potassium-chloride cotransporters.

To obtain nominally $\mathrm{Ca}^{2+}$-free solution, the calcium buffer EGTA ( 1 mM; Aldrich, Milwaukee, WI) was added to an ACSF prepared omitting $\mathrm{CaCl}_{2}$. Thapsigargin ( $5 \mu \mathrm{M}$; Sigma) was used to deplete intracellular stores by inhibiting the $\mathrm{Ca}^{2+}$-ATPase, and ethosuximide $(0.09-0.9 \mathrm{mM}$; Sigma) and $\omega$-conotoxin GVIA $(0.3 \mu \mathrm{m}$; Alomone Labs, Jerusalem, Israel) were used to inhibit $\mathrm{T}$ - and $\mathrm{N}$-type voltage-gated calcium channels (VGCCs), respectively. All drugs were prepared as $1000 \times$ concentrated stock solution.

Data and statistical analysis. Electrophysiological data were analyzed using locally designed software (MCE). The measured membrane potentials were corrected for liquid junction potential, seal, and input resistance as described previously (Tyzio et al., 2003). $E_{\text {anion }}$ was evaluated from a series of GABA responses obtained at different holding potentials, at $>30 \mathrm{~s}$ intervals. Intracellular $\left[\mathrm{Cl}^{-}\right]$was calculated from $E_{\text {anion }}$ using a derivation from the Hodgkin-Katz-Goldman equation, assuming a permeability ratio between $\mathrm{Cl}^{-}$and $\mathrm{HCO}_{3}^{-}$anions of 0.25 , with a $\left[\mathrm{HCO}_{3}^{-}\right]$ of 26 and $16 \mathrm{~mm}$ in the extracellular and intracellular solutions, respectively (Kaila, 1994).

The effect of age and pipette $\left[\mathrm{Cl}^{-}\right]$on $E_{\text {anion }}$ was evaluated using a two-way ANOVA. To measure the effect of drug administrations when imaging calcium, the peak values from three consecutive, stable, control responses to GABA (5-6 min apart) were averaged and compared with the average peak of three consecutive stable responses during bath application of the tested drug. Statistical significance of the effect was calculated using the paired Student's $t$ test, in which the paired values were the average peak under control or drug condition for each tested neuron. $p<$ 0.05 was considered as indicative of a statistically significant difference. Values are expressed as mean \pm SEM. 


\section{Results}

GABA induces a rise in $\left[\mathrm{Ca}^{2+}\right]_{\mathrm{i}}$ mediated by $\mathrm{GABA}_{\mathrm{A}}$ receptors until postnatal day 21

Calcium imaging was chosen as a functional approach to record the action of GABA during development. Indeed, GABA has been shown to produce a rise in $\left[\mathrm{Ca}^{2+}\right]_{\mathrm{i}}$ in slices of immature brain and spinal ventral horn (Yuste and Katz, 1991; Lin et al., 1994; Leinekugel et al., 1995; Owens et al., 1996; Kulik et al., 2000; Eilers et al., 2001; Yamada et al., 2004; Wang et al., 2005) and in cultures of embryonic dorsal horn neurons (Reichling et al., 1994; Wang et al., 1994).

We locally applied GABA (1 mM) by pressure ejection (30 ms) on identified LI neurons in slices obtained from rats aged P1P30. Identification of LI neurons was based on previously established criteria, including their distance from the dorsal white matter $(25.6 \pm 3.7 \mu \mathrm{m})$ and the distinctive appearance of laminas I and II in sagittal slices (Chery and De Koninck, 1999; Keller et al., 2001). During the first postnatal week, GABA induced a rise in $\left[\mathrm{Ca}^{2+}\right]_{\mathrm{i}}$ in $81.5 \pm 2.6 \%$ of LI neurons (P0-P7; $\left.n=65\right)$. The number of responding neurons decreased with age: $47.9 \pm 2.3 \%$ of neurons responded with a rise in $\left[\mathrm{Ca}^{2+}\right]_{\mathrm{i}}$ at $\mathrm{P} 8-\mathrm{P} 15(n=96)$ and only $4.9 \pm 2.2 \%$ at P16-P25 $(n=62)$. The viability of all cells was confirmed by evoking a calcium response to brief application of $\mathrm{KCl}$. Figure $1 A$ illustrates the evolution of the proportion of LI neurons responding to GABA with a rise in $\left[\mathrm{Ca}^{2+}\right]_{\mathrm{i}}$. The smooth curve through the data points indicates that, between P10 and $\mathrm{P} 11,50 \%$ of neurons respond to $\mathrm{GABA}$ with a rise in $\left[\mathrm{Ca}^{2+}\right]_{\mathrm{i}}$. The $\left[\mathrm{Ca}^{2+}\right]_{\mathrm{i}}$ response was completely inhibited by $25 \mu \mathrm{M}$ bicuculline in 17 of 18 neurons tested (P0-P18), confirming that this effect of GABA was mediated by activation of $\mathrm{GABA}_{\mathrm{A}}$ receptors (Fig. $1 \mathrm{~B}$ ).

The experiments presented above were performed in the presence of $1 \mu \mathrm{M}$ TTX to ensure that the observed rise in $\left[\mathrm{Ca}^{2+}\right]_{\mathrm{i}}$ arose from a direct effect of GABA on the neuron(s) under study. However, we conducted similar experiments in $10 \mu \mathrm{M}$ CNQX to test the effect of TTX on the amplitude of the calcium response induced by GABA. At P5, when $1 \mu \mathrm{M}$ TTX was added to the bathing solution, the amplitude of the calcium response was decreased to $41.5 \pm 9.0 \%(p<0.001)$ of the control response amplitude in CNQX alone $(n=13)$ (Fig. $1 C)$. These results demonstrated that a TTX-sensitive component was involved in the amplification of the GABA-induced rise in $\left[\mathrm{Ca}^{2+}\right]_{\mathrm{i}}$ at P5. This sodium conductance may reflect action potentials but also the opening of persistent sodium channels (Magistretti et al., 1999). In contrast, the calcium response was not significantly inhibited by TTX at P10 (90.4 $\pm 5.1 \%$ of control response; $n=5 ; p>0.1$ ).

It should be noted that the rise in $\left[\mathrm{Ca}^{2+}\right]_{\mathrm{i}}$ is a functional response that may be caused by different mechanisms, involving or not TTX-sensitive channels, and thus represents a complementary approach for the study of the cellular actions of GABA to voltage recordings and monitoring of firing activity. However, a rise in $\left[\mathrm{Ca}^{2+}\right]_{\mathrm{i}}$ can be differentially interpreted depending on the source of calcium: intracellular stores or extracellular medium. If the rise in $\left[\mathrm{Ca}^{2+}\right]_{\mathrm{i}}$ reflects a membrane depolarization and the opening of VGCCs, then this measure would indicate GABAinduced depolarization and consequently decreased inhibition of LI neurons. We therefore investigated further the mechanism of GABA-induced rise in $\left[\mathrm{Ca}^{2+}\right]_{\mathrm{i}}$.

\section{The rise in $\left[\mathrm{Ca}^{2+}\right]_{\mathrm{i}}$ induced by GABA involves the entry of extracellular calcium}

To test the implication of extracellular calcium, we challenged our spinal slices with an ACSF nominally devoid of $\mathrm{Ca}^{2+}(0 \mathrm{~mm}$ $\mathrm{Ca}^{2+}$ plus $1 \mathrm{~mm}$ EGTA). Regardless of the age, the rise in $\left[\mathrm{Ca}^{2+}\right]_{\mathrm{i}}$
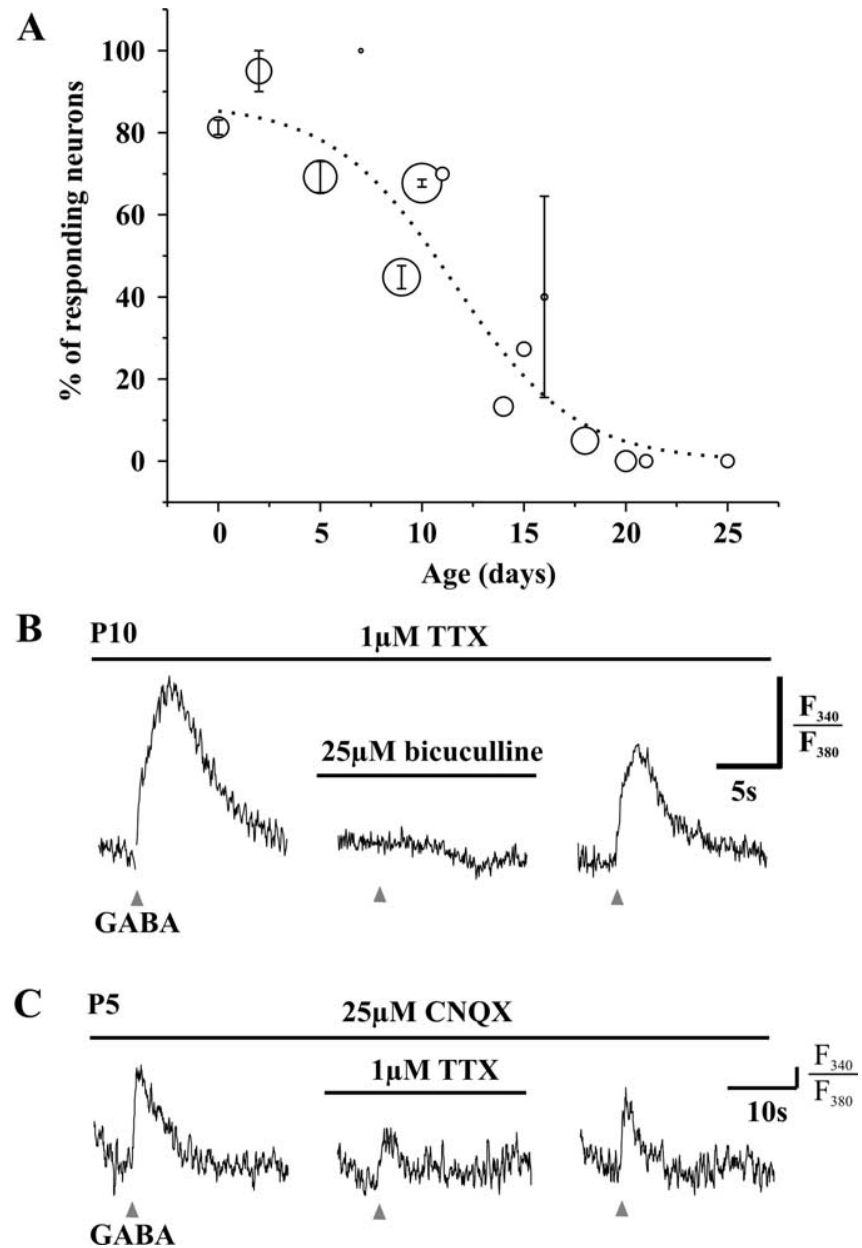

Figure 1. Short (20-30 ms) local applications of GABA (1 mm) produce a rise in $\left[\mathrm{Ca}^{2+}\right]_{i}$ in developing lamina I neurons. $A$, Evolution of this effect (in $1 \mu \mathrm{M} \mathrm{TTX).} \mathrm{Circles} \mathrm{are} \mathrm{centered} \mathrm{at} \mathrm{the}$ mean percentage of responding neurons, and their diameter is proportional to the number of neurons tested with GABA at each age $(n=3-31)$; the error bars represent the SEM for mean percentages obtained from different days of experiment on animals of the same age $(n=$ 1-4). $\boldsymbol{B}$, The rise in $\left[\mathrm{Ca}^{2+}\right]_{\mathrm{i}}$ induced (in $1 \mu \mathrm{M}$ TTX) by GABA applications (triangles) is inhibited by $25 \mu \mathrm{m}$ bicuculline (horizontal bar). C, GABA also induces a rise in $\left[\mathrm{Ca}^{2+}\right]_{\mathrm{i}}$ in $10 \mu \mathrm{m}$ CNQX. At $\mathrm{P} 5$, this effect is partially inhibited by $1 \mu \mathrm{m}$ TTX. The $\left[\mathrm{Ca}^{2+}\right]_{\mathrm{i}}$ response is expressed as the ratio of emission from 340 and $380 \mathrm{~nm}$ excitation wavelength $\left(F_{340} / F_{380}\right)$; the vertical bar represents $5 \%$ of the baseline ratio.

induced by GABA was abolished or greatly reduced in the calcium-free solution $(p<0.0001)$ (Fig. $2 A, C)$ : in P5, P9-P11, and $\mathrm{P} 15$ neurons, within a 15 min perfusion of the calcium-free solution, the responses were, respectively, $0.8 \pm 0.8 \%(n=9)$, $0.0 \pm 0.0 \%(n=7)$, and $3.1 \pm 3.1 \%$ of control responses $(n=7)$. The responses to GABA recovered to $81.2 \pm 12.3 \%(n=23)$ of the control response within $10 \mathrm{~min}$ after returning to normal ACSF (Fig. 2A).

The fact that extracellular $\mathrm{Ca}^{2+}$ is necessary to trigger the rise in $\left[\mathrm{Ca}^{2+}\right]_{\mathrm{i}}$ induced by GABA does not imply that $\mathrm{Ca}^{2+}$ released from intracellular stores is not involved in amplifying the response. We applied the $\mathrm{Ca}^{2+}$-ATPase blocker thapsigargin (5 $\mu \mathrm{M})$ to deplete intracellular stores of calcium (Thastrup et al., 1990). This treatment did not produce a significant decrease in the response $(80.7 \pm 7.1 \%$ of the control response; $p>0.1 ; n=5$; P10) (Fig. $2 B, C$ ), suggesting that calcium-induced calcium release phenomenon is not a major contributor to the rise in $\left[\mathrm{Ca}^{2+}\right]_{\mathrm{i}}$ induced by GABA in young LI neurons. Note in Figure $2 B$ the prolongation of the decay phase of the calcium response 
A $\quad \mathbf{P 1 0}$

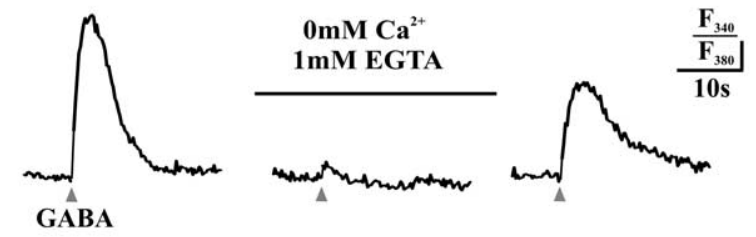

B $\quad \mathbf{P 1 0}$
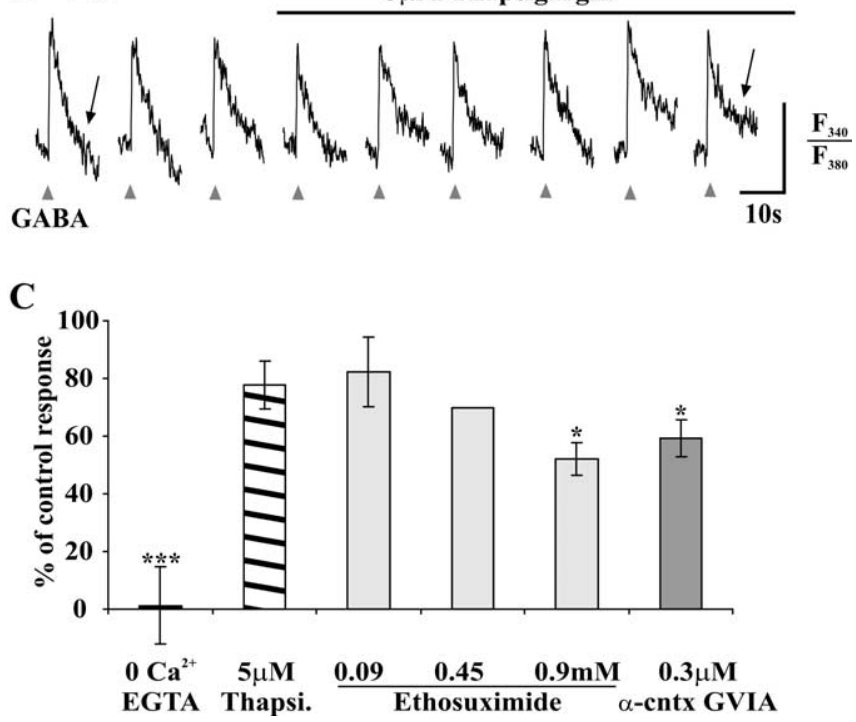

Figure 2. The GABA-induced rise in $\left[\mathrm{Ca}^{2+}\right]_{\mathrm{i}}$ (in $1 \mu \mathrm{MTTX}$ ) involves the entry of extracellular $\mathrm{Ca}^{2+}$ through VGCCs. $A$, The calcium response to brief $(20-30 \mathrm{~ms})$ GABA application (triangles) is inhibited in a nominally $\mathrm{Ca}^{2+}$-free $\mathrm{ACSF}\left(0 \mathrm{Ca}^{2+}\right.$ plus $1 \mathrm{~mm}$ EGTA; horizontal bar). The vertical bar represents $5 \%$ of the baseline $F_{340} / F_{380}$ ratio. $B$, Bath application of the $\mathrm{Ca}^{2+}$-ATPase blocker thapsigargin ( $5 \mu \mathrm{m}$; horizontal bar) does not affect the amplitude of GABA-induced rise in $\left[\mathrm{Ca}^{2+}\right]_{i}(5$ min apart); note, however, the prolonged decay phase of the response during the treatment (arrows; see Results). The vertical bar represents $5 \%$ of the baseline $F_{340} / F_{380}$ ratio. $C$, Mean effect of the abovementioned treatments and of antagonists of VGCC, on the control response to GABA in normal ACSF. The error bars represent the SEM of measurements on different neurons. ${ }^{*} p<0.05$ and ${ }^{* * *} p<0.001$ versus the control response (paired $t$ test). Thapsi, Thapsigargin; $\alpha$-cntx GVIA, $\alpha$-conotoxin GVIA.

during the application of thapsigargin, indicating that $\mathrm{Ca}^{2+} \mathrm{re}-$ capture by intracellular stores was effectively inhibited by the dose of blocker used (Shmigol et al., 1994).

Because the main source of calcium appeared to be the extracellular medium, we then investigated the types of VGCCs involved in the $\mathrm{GABA}_{\mathrm{A}}$ receptor-mediated entry of calcium. In adult rats, most types of VGCCs have been identified by immunocytochemistry or in situ hybridization in the spinal dorsal horn (Westenbroek et al., 1998; Talley et al., 1999). Moreover, in this region, both low- and high-voltage-activated calcium currents have been recorded (Ryu and Randic, 1990; Heinke et al., 2004), implicated in the generation of spontaneous and evoked EPSCs (Bao et al., 1998) and in synaptic plasticity (Ikeda et al., 2003).

Administration of the T-type VGCC inhibitor ethosuximide (Gomora et al., 2001) on P7-P15 spinal slices produced a dosedependent inhibition of the rise in $\left[\mathrm{Ca}^{2+}\right]_{i}$ induced by GABA (Fig. $2 C$ ), reaching a reduction of the response to $52.2 \pm 5.6 \%$ of control at a concentration of $0.9 \mathrm{~mm}(n=17 ; p<0.005)$. The $\mathrm{N}$-type VGCC inhibitor $\omega$-conotoxin GVIA [0.3 $\mu \mathrm{M}$ (Jones and Marks, 1989; Whyte and Greenfield, 2002)] induced a similar reduction of the response to $59.2 \pm 6.3 \%$ of the control response $(n=8 ; p<0.01)$ (Fig. 2C).

Altogether, these results indicate that the GABA-induced rise

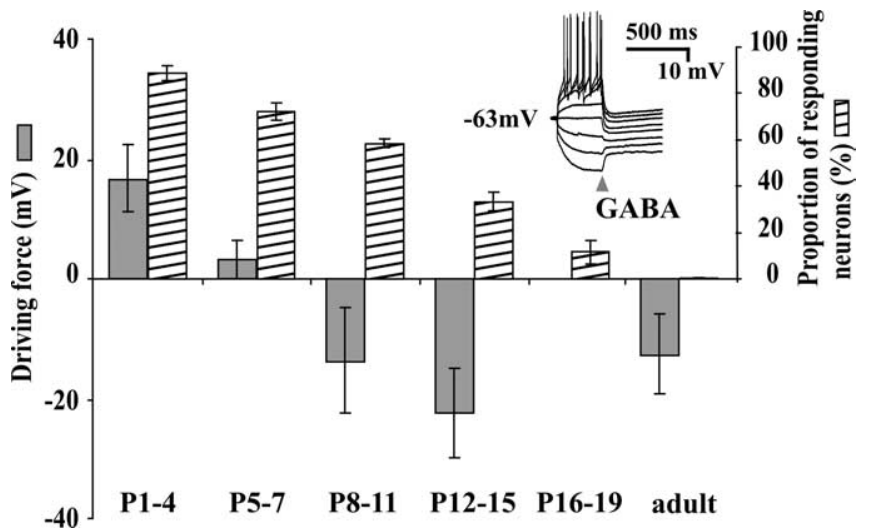

Figure 3. Time course of the evolution of the driving force of anions and the percentage of neurons responding to brief GABA applications (20-30 ms, in $1 \mu \mathrm{M} \mathrm{TTX)} \mathrm{with} \mathrm{a} \mathrm{rise} \mathrm{in}\left[\mathrm{Ca}^{2+}\right]_{\mathrm{i}}$. The driving force for individual neurons is calculated from the measure of the resting potential and the reversal potential for anions in perforated patch using gramicidin. Inset, Example of recordings used to measure $E_{\text {anion }}$ (in current-clamp mode in this case). Each trace shows a voltage response to $10 \mathrm{pA}$ incremental current step; peak response was measured at $200 \mathrm{~ms}$ from GABA puff (arrowhead).

in $\left[\mathrm{Ca}^{2+}\right]_{\mathrm{i}}$ is mainly attributable to the entry of extracellular calcium and that both T- and N-type VGCCs are involved at P7$\mathrm{P} 15$. The involvement of VGCCs indicates that the membrane is effectively depolarized during the response to GABA. Neurons from neonatal rats have been demonstrated to be depolarized by GABA; the high proportion of neurons responding to GABA with a rise in $\left[\mathrm{Ca}^{2+}\right]_{\mathrm{i}}$ during the second and third postnatal week was however unexpected. To confirm that these involved depolarization, we decided to directly investigate the membrane voltage responses to GABA through patch-clamp recordings.

\section{Mismatch between maturation of $E_{\text {anion }}$ and calcium responses to $\mathrm{GABA}$}

Neurons from neonates are known to have more positive $E_{\text {anion }}$ than adult neurons (Ben Ari, 2002). When $E_{\text {anion }}$ is more positive than the resting membrane potential $\left(V_{\text {rest }}\right)$ of the neuron, the opening of the anion-permeable channel of $\mathrm{GABA}_{\mathrm{A}}$ receptors at rest produces a depolarization. We decided to investigate whether such depolarization was the cause of our observed $\mathrm{GABA}_{\mathrm{A}}$ receptor-mediated rise in $\left[\mathrm{Ca}^{2+}\right]_{\mathrm{i}}$.

$\mathrm{GABA}_{\mathrm{A}}$ receptor-mediated depolarizations have been reported in the superficial dorsal horn (mainly lamina II) of neonatal spinal cord (Baccei and Fitzgerald, 2004). By P6, however, the vast majority of neurons recorded in that study were hyperpolarized by GABA from rest. A difference in the spinal region under study could be the cause of a discrepancy between those electrophysiological results and our calcium-imaging observations. To verify this, we undertook a similar characterization of $E_{\text {anion }}$ and $V_{\text {rest }}$ in neonatal LI neurons. In P1-P30 slices, 30 neurons were analyzed using the perforated patch-clamp technique; gramicidin was used as a perforating agent, producing $\mathrm{Cl}^{-}$impermeant pores (Abe et al., 1994; Kyrozis and Reichling, 1995). In all cases, GABA was briefly $(20 \mathrm{~ms})$ applied in the vicinity of the neuron held at different voltages in the voltage- and/or currentclamp mode. This and all subsequent experiments were performed in the presence of CNQX and APV. The peak response was measured within $200 \mathrm{~ms}$ of the drug application (Fig. 3, inset). Measured at this timescale, GABA induced a depolarization (or an inward current in voltage clamp) from rest in $83.3 \%$ of neurons from $\mathrm{P} 1-\mathrm{P} 4$ slices, $66.7 \%$ of neurons from P5-P7 slices, 
$28.6 \%$ of neurons from P8-P11 slices $(n=6-14)$, and in only 1 of 11 neurons in slices from rats older than P12 (9\%). The driving force $\left(E_{\text {anion }}-V_{\text {rest }}\right)$ was measured for each neuron, and the average of this value for each age group is plotted in Figure 3. The maturation profile of GABA responses in our LI sample was overall very similar to that described in lamina II by Baccei and Fitzgerald (2004). For the purpose of comparison, we also plotted on Figure 3 the percentage of LI neurons responding to GABA with a rise in $\left[\mathrm{Ca}^{2+}\right]_{\mathrm{i}}$ as a function of age. During the second postnatal week, there is an apparent mismatch between these two sets of data, given that one-half of the neurons still display a calcium response to GABA whereas almost two-thirds of the cells are initially hyperpolarized by GABA. Because these results were obtained with two approaches used independently, it did not allow the elucidation of the mechanism of GABA action. In addition, the calcium responses occurred at a different timescale than that of the measured polarizations (several seconds vs milliseconds) (compare traces in Figs. 1 and 2 with inset in Fig. 3). We thus decided to combine the two approaches to directly monitor the types of voltage responses accompanying the $\mathrm{GABA}_{\mathrm{A}}$ receptor-mediated rise in $\left[\mathrm{Ca}^{2+}\right]_{\mathrm{i}}$.

A biphasic response to GABA can induce a rise in $\left[\mathrm{Ca}^{2+}\right]_{\mathrm{i}}$ To elucidate the mismatch between the maturation of calcium responses and $E_{\text {anion, }}$, we focused on P10-P11 neurons, in which this mismatch was the most apparent. For these experiments, neurons were filled with the calcium indicator fura-2 through the patch pipette, in whole-cell configuration (current-clamp mode). The pipette solution was chosen as to impose a modest $\mathrm{Cl}^{-}$load $(9 \mathrm{~mm})$. To match the timescale of calcium responses, voltage recordings were monitored over several seconds. On this timescale, the voltage responses to brief GABA applications (20 $\mathrm{ms}$ ), from resting membrane potential, were of three types: hyperpolarization, depolarization, or biphasic responses consisting of a primary hyperpolarizing phase followed by a secondary depolarizing phase (Fig. 4).

Depolarizations in response to GABA were accompanied by a rise in $\left[\mathrm{Ca}^{2+}\right]_{\mathrm{i}}$, whereas hyperpolarizations were not (Fig. $4 A$ ). Interestingly, biphasic responses to GABA could also be accompanied by a rise in $\left[\mathrm{Ca}^{2+}\right]_{\mathrm{i}}($ Fig. $4 \mathrm{~B})$, suggesting that the second, depolarizing phase was sufficient to trigger the opening of VGCCs. A biphasic response to GABA from rest could be turned into a depolarizing one by prehyperpolarizing the neuron, and the size of the calcium response was proportional to the amplitude of the depolarization induced by GABA application (Fig. $4 B$ ). This is consistent with the result in Figure 2, indicating that the rise in $\left[\mathrm{Ca}^{2+}\right]_{\mathrm{i}}$ involved activation of VGCCs. Alternatively, the greater rise in $\left[\mathrm{Ca}^{2+}\right]_{i}$ could be attributable to a voltage dependence of the calcium response per se. To test for this, we performed control recordings of calcium responses triggered by 5-s-long depolarizing steps of fixed amplitude instead of GABA applications. When the neurons were hyperpolarized, the calcium responses to constant depolarizing pulses were reduced or abolished by sufficient prehyperpolarization $(n=3$ cells; result not shown). The greater rise in $\left[\mathrm{Ca}^{2+}\right]_{\mathrm{i}}$ in response to GABA when the neuron is prehyperpolarized therefore appears to be attributable to the larger amplitude of the depolarizing phase.

A third, hyperpolarizing phase (Fig. $4 B$, open arrowhead) was occasionally observed after GABA applications. The reversal potential of this phase suggested that it could be attributable to a $\mathrm{K}^{+}$ current. Indeed, triphasic responses were never observed with $\mathrm{Cs}^{+}$-filled pipettes $(n=13$; result not shown). To test whether the third phase involved activation of $\mathrm{GABA}_{\mathrm{B}}$ receptors, we re-

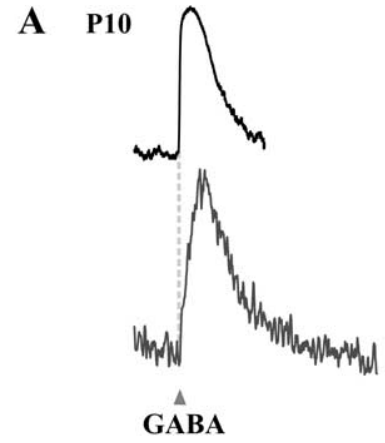

P10

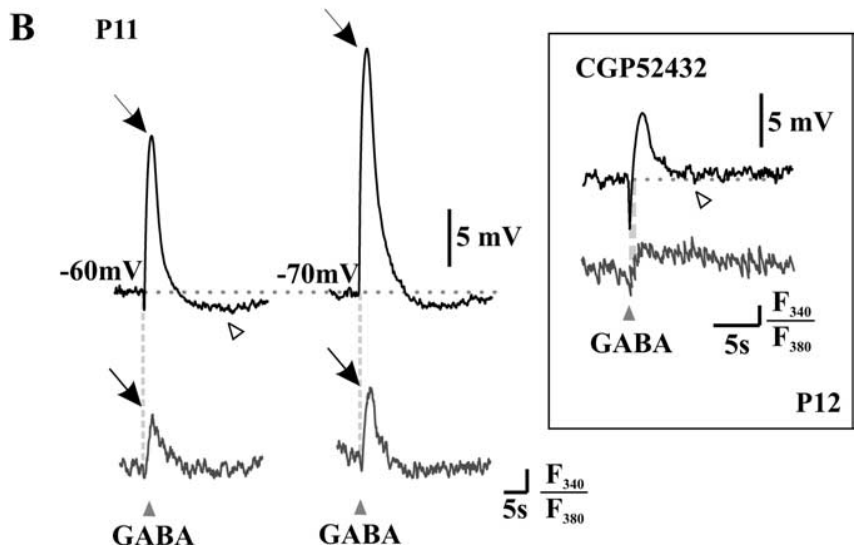

Figure 4. Rise in $\left[\mathrm{Ca}^{2+]}\right.$ is associated with the depolarizing phases of membrane responses to brief GABA applications ( $20-30 \mathrm{~ms}$ ). Simultaneous patch-clamp recordings (current-clamp mode; top lines) and calcium imaging (bottom lines) were used to analyze the responses to $G A B A_{A}$ agonist applications (arrowheads). $\boldsymbol{A}$, Recordings from two neurons illustrating that depolarizing responses to $\mathrm{GABA}$ are accompanied by a rise in $\left[\mathrm{Ca}^{2+}\right]_{i}($ left), whereas hyperpolarizing responses are not (right). $\boldsymbol{B}$, Recordings from a third neuron illustrating that biphasic responses to GABA are also accompanied by a small calcium response (left), whose amplitude increases (arrows) as the neuron is hyperpolarized (from -60 to $-70 \mathrm{mV}$ using current injections) to present a smaller, pure depolarizing response (right). Note, however, a third hyperpolarizing phase at the end of the response (open arrowhead). Inset, When GABA was applied in the presence of the $G A B A_{B}$ receptor antagonist CGP 52432, this third phase was absent (open arrowhead, compare with traces on the left), yet the biphasic response was still accompanied by a rise in $\left[\mathrm{Ca}^{2+}\right]_{\mathrm{i}}$. The vertical bar represents $1 \%$ of the baseline $F_{340} / F_{380}$ ratio.

corded, in a different set of experiments, responses to GABA in the presence of the $\mathrm{GABA}_{\mathrm{B}}$ antagonist CGP 52432. Under these conditions, GABA also produced biphasic but no triphasic responses; such biphasic responses were accompanied by a rise in $\left[\mathrm{Ca}^{2+}\right]_{\mathrm{i}}$ (Fig. $4 \mathrm{~B}$, inset). Similarly, biphasic but no triphasic responses were also observed using the $\mathrm{GABA}_{\mathrm{A}}$ receptor-specific agonist muscimol (see Fig. 6B).

These responses to GABA and muscimol were recorded in the presence of $10 \mu \mathrm{M}$ CNQX. Biphasic responses were also observed in $1 \mu \mathrm{M}$ TTX (data not shown), indicating that network activity was not involved in the generation of the depolarizing phase. We decided to further analyze the biphasic responses because they appeared to be a cause of $\mathrm{GABA}_{\mathrm{A}}$-mediated rise in $\left[\mathrm{Ca}^{2+}\right]_{\mathrm{i}}$ in P10-P11 neurons.

\section{$E_{\text {anion }}$ changes during the response to GABA}

Biphasic responses to GABA have been documented previously, in particular after sustained stimulation of adult neurons in the hippocampus (Staley et al., 1995; Kaila et al., 1997). It has been proposed that the depolarization is attributable to a dominating outward flux of bicarbonate, because the intracellular accumulation of $\mathrm{Cl}^{-}$collapses the $\mathrm{Cl}^{-}$gradient (Staley et al., 1995), possi- 

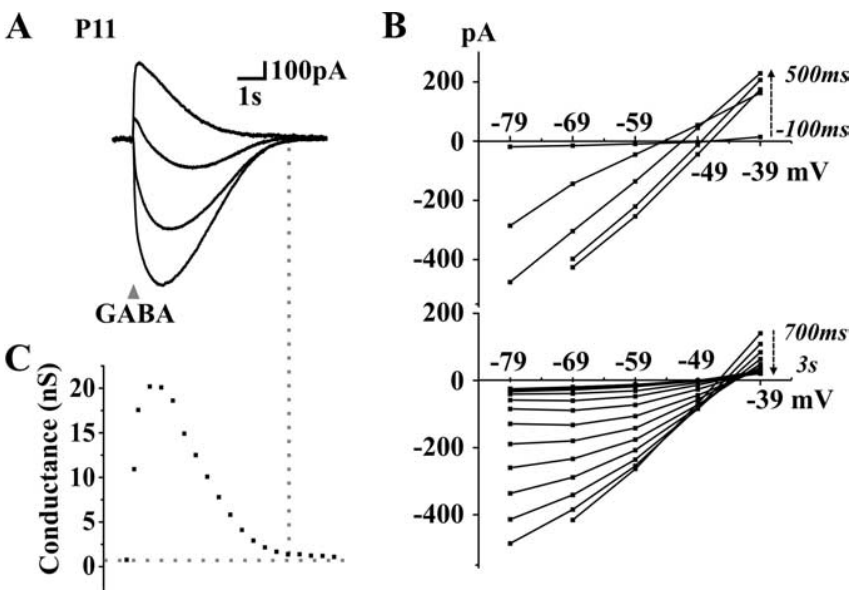

Figure 5. Current-voltage analysis of the responses to GABA in a neuron presenting a biphasic response at rest. $A$, Voltage-clamp traces of the responses to brief (20 ms) GABA applications at different holding potentials $\left(-20\right.$ to $+30 \mathrm{mV}$ from rest; $V_{\text {rest }}$ of $-49 \mathrm{mV}$ ). $\boldsymbol{B}, I-V$ curves at different time points ( $200 \mathrm{~ms}$ apart) during the first $500 \mathrm{~ms}$ (top) and after $3 \mathrm{~s}$ (bottom) of the current response to GABA. $C$, Evolution of the cell conductance during the response, as calculated from the slope of $I-V$ traces at different time points.

bly accompanied by a bicarbonate-induced extracellular accumulation of $\mathrm{K}^{+}$(Smirnov et al., 1999). We performed a series of experiments to evaluate whether GABA-induced biphasic responses in P10-P11 spinal LI neurons could be explained by these mechanisms.

We first analyzed the current-voltage $(I-V)$ relationship of biphasic responses to GABA. These experiments were conducted in voltage-clamp mode to prevent activation of voltagedependent conductances. Biphasic current responses were also observed in this recording mode (Fig. 5A). After holding the neuron at different voltages (between -30 and $+30 \mathrm{mV}$ from its resting membrane potential), GABA was applied and $I-V$ curves were plotted at different time points (100-200 ms apart) during the response to GABA (Fig. $5 A, B$ ). The membrane conductance was calculated as the slope of these $I-V$ curves (Fig. $5 C$ ). One observation that could suggest that the depolarization is mainly attributable to extracellular accumulation of $\mathrm{K}^{+}$would be that the conductance decays faster than the current response, yielding a point at which a current is observed without a measurable change in conductance from rest (Kaila et al., 1997). In our case, the membrane conductance was enhanced throughout the response (Fig. 5C), indicating that the rebound inward current involved an increased ionic flux (yet not excluding the possibility of some $\mathrm{K}^{+}$accumulation). The reversal potential changed with time during the response (Fig. $5 B$ ), suggesting that the concentrations of ions (intracellular or extracellular) permeating through $\mathrm{GABA}_{\mathrm{A}}$ channels changed during the response (Staley and Proctor, 1999).

To test this hypothesis, we used repeated applications of GABA. In voltage-clamp mode, we recorded biphasic postsynaptic responses to GABA (Fig. 6A, left). We then performed a second GABA application before the end of the first response (Fig. $6 \mathrm{~A}$, middle). If there were no (or little) change in $E_{\text {anion }}$ during the first response, the second response should look like the first one, i.e., be biphasic (Kaila et al., 1997; Perkins, 1999). However, the second response was monophasic, only composed of the inward current component. A third application, produced after the same time interval ( $2 \mathrm{~s}$ ), had the same effect (Fig. 6A, right). This result suggests the following: (1) that, at rest, $E_{\text {anion }}$ is more negative than $V_{\text {rest }}$, inducing an initial outward current resulting
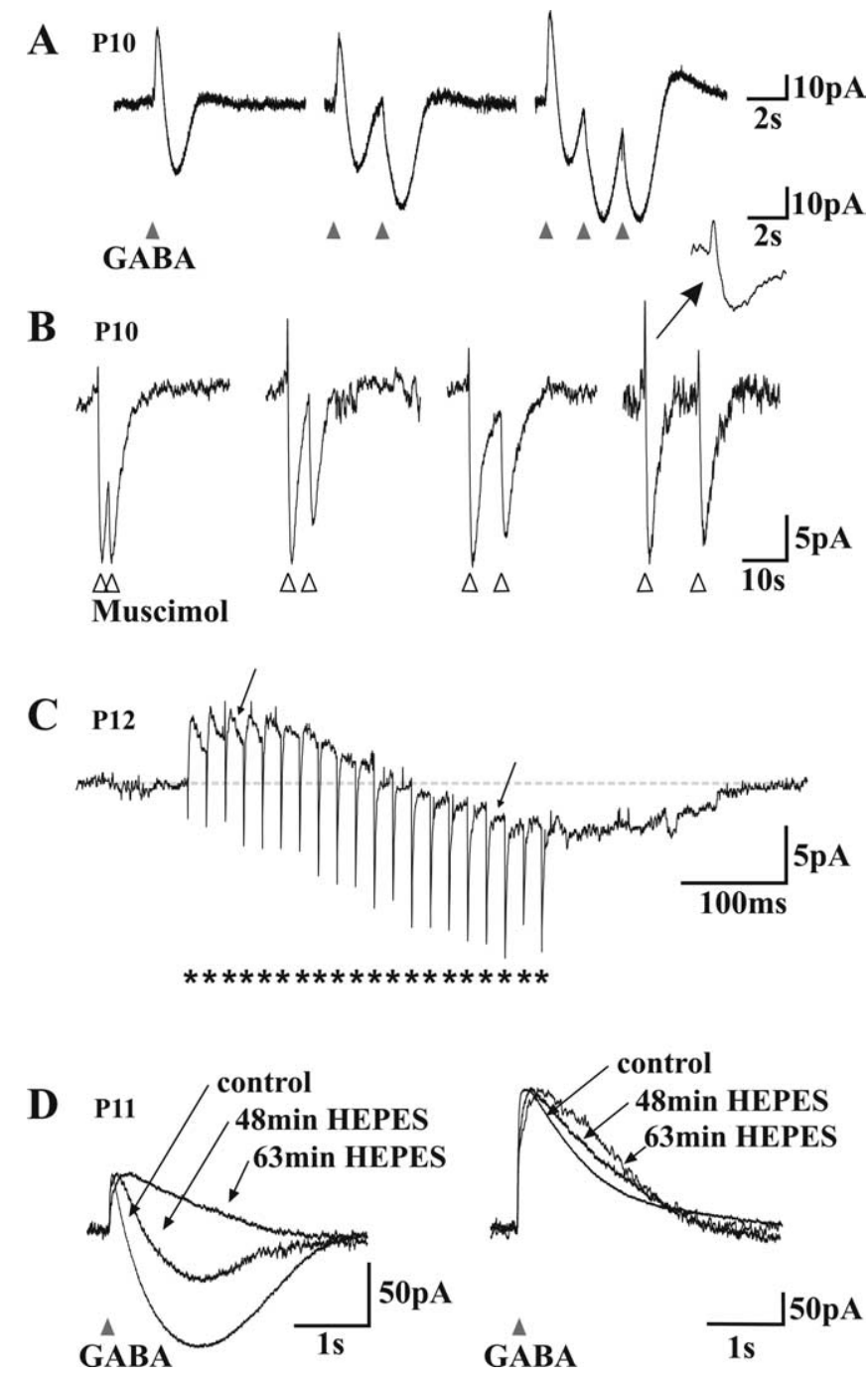

Figure 6. Mechanism of $\mathrm{GABA}_{\mathrm{A}}$ receptor-mediated biphasic responses. $\boldsymbol{A}$, Voltage-clamp recordings of the response of a neuron to different patterns of brief (20 ms) GABA applications The cell displayed a biphasic (outward/inward) response to GABA (left). Note that the second (middle) and third (right) application of GABA with 2 s intervals produce a monophasic inward current. Note also the small outward tail response after repetitive applications. $\boldsymbol{B}$, Voltageclamp recordings of the response of a neuron to pairs of brief $(20 \mathrm{~ms})$ muscimol applications ( 5 , 10,15 , or 25 s interval; in the presence of (GP 54523). The second response was also monophasic when superimposed on the inward phase of the first response. Note that repetitive applications of muscimol do not induce the small outward tail. Inset, An enlargement on a faster timescale (same as in $\boldsymbol{A}$ ). Traces are normalized to the amplitude of the first response to help comparisons. C, Voltage-clamp trace of a neuron responding to a train of focal electrical stimulations (short burst of 20 pulses, indicated by asterisks, at 25 ms intervals). Note the slowly developing inward phase and how individual synaptic currents have their polarity inverted (arrows) during this late inward phase. D, Effect of the replacement of the bicarbonate buffer by a HEPES buffer in the ACSF. Left, The inward phase of the biphasic responses observed near resting potential faded with time in HEPES. Right, At depolarized holding potentials $(-39 \mathrm{mV})$, in which outward only responses were recorded, the decay phase of the responses was prolonged in HEPES. Traces are normalized to the amplitude of the first response to allow for comparison of the kinetics.

from $\mathrm{GABA}_{\mathrm{A}}$ receptor opening, (2) then, during the biphasic response to $\mathrm{GABA}, E_{\text {anion }}$ changes and remains positive with respect to $V_{\mathrm{m}}$ for prolonged periods of time ( $\gg 2 \mathrm{~s}$ ); (3) therefore, a second GABA application will lead to an inward current.

As previously mentioned, GABA occasionally induced a triphasic response. Although hardly detectable after a single application in voltage-clamp mode (Fig. $6 \mathrm{~A}$, left), the outward third phase was amplified after repetitive GABA applications (Fig. 6A, 
right). Our recordings in current clamp suggested that the third phase was attributable to the activation of $\mathrm{GABA}_{\mathrm{B}}$ receptors (Fig. $4 B)$. Similarly, when muscimol was used as a specific $\mathrm{GABA}_{\mathrm{A}}$ agonist, and in the presence of CGP52432, only biphasic responses were observed even after repetitive applications (Fig. $6 B)$, confirming that the third phase was attributable to a $G_{A B A}$ component.

To determine whether a shift in $E_{\text {anion }}$ during the response to GABA is relevant to synaptic transmission in developing lamina I neurons, we tested whether synaptically released GABA could similarly induce a biphasic response. We analyzed the response of P10-P12 lamina I neurons to focal electric stimulations in the presence of the glutamatergic receptors antagonists DNQX (10 $\mu \mathrm{M})$ and AP-5 $(40 \mu \mathrm{M})$ to isolate monosynaptic IPSCs. In each cell tested, we applied trains of 5-20 stimuli at interpulse intervals of 10 to $50 \mathrm{~ms}$ (i.e., $20-100 \mathrm{~Hz}$ intraburst frequency). These trains were comparable in length and internal frequencies to bursts of activity observed in dorsal horn interneurons in vivo [both spontaneously occurring bursts and those in response to afferent input (De Koninck and Henry, 1991, 1994; De Koninck et al., 1992)]. In 9 of 23 cells tested in which outward IPSCs were obtained in response to a single stimulus, a biphasic response with a slowly developing inward component was obtained with short bursts of stimuli (in four cases with $20 \mathrm{~Hz}$ bursts, seven cases with $40 \mathrm{~Hz}$ bursts, and nine cases with $100 \mathrm{~Hz}$ bursts). Figure 6C illustrates a biphasic response to a $40 \mathrm{~Hz}$ burst (20 pulses). During the inward phase of the biphasic response, individual stimulusevoked PSCs were turned into inward events (Fig. 6C). This confirmed that the inward phase of biphasic responses was attributable to a reversal of the anion gradient as observed with responses to exogenous GABA or muscimol (Fig. 6A,B). Thus, physiologically relevant trains of IPSCs are sufficient to cause biphasic responses.

Altogether, these results suggest that the biphasic responses to GABA observed in P10-P11 spinal LI neurons are attributable to a change in $E_{\text {anion }}$ during the response. Because the bicarbonate gradient is likely stabilized by the fast equilibration of $\mathrm{CO}_{2}$ across the cell membrane (Kaila, 1994), an intracellular accumulation of $\mathrm{Cl}^{-}$appears to be the most probable cause of the shift in $E_{\text {anion }}$ during the GABA response. With the collapse of the driving force for $\mathrm{Cl}^{-}$, the outward $\mathrm{HCO}_{3}^{-}$flux would then dominate the GABA response yielding a net inward current. To test this hypothesis, we replaced the bicarbonate buffer with HEPES in the ACSF (see Materials and Methods). Figure $6 \mathrm{D}$ illustrates the effect of this substitution. The inward component of biphasic responses was gradually abolished in HEPES. Note also, at more depolarized potentials, the slower rise and decay kinetics of outward currents in HEPES, consistent with the loss of an inward component. These results indicate that the $\mathrm{HCO}_{3}^{-}$current is shaping the late phase of the GABA response. In particular, at membrane potentials slightly depolarized from $E_{\mathrm{Cl}-}$, this phenomenon yields a biphasic response characterized by an initial outward component dominated by $\mathrm{Cl}^{-}$flux, followed by an inward component dominated by $\mathrm{HCO}_{3}^{-}$flux.

Notwithstanding the fact that P10-P11 neurons have a mean $E_{\text {anion }}$ close to that of adult neurons, their biphasic responses to GABA suggest a weaker $\mathrm{Cl}^{-}$extrusion. To test this, we measured the net $\mathrm{Cl}^{-}$extrusion capacity (i.e., resulting from the combined extrusion and intrusion activity) of neurons at different ages by challenging them with an intracellular $\mathrm{Cl}^{-}$load.
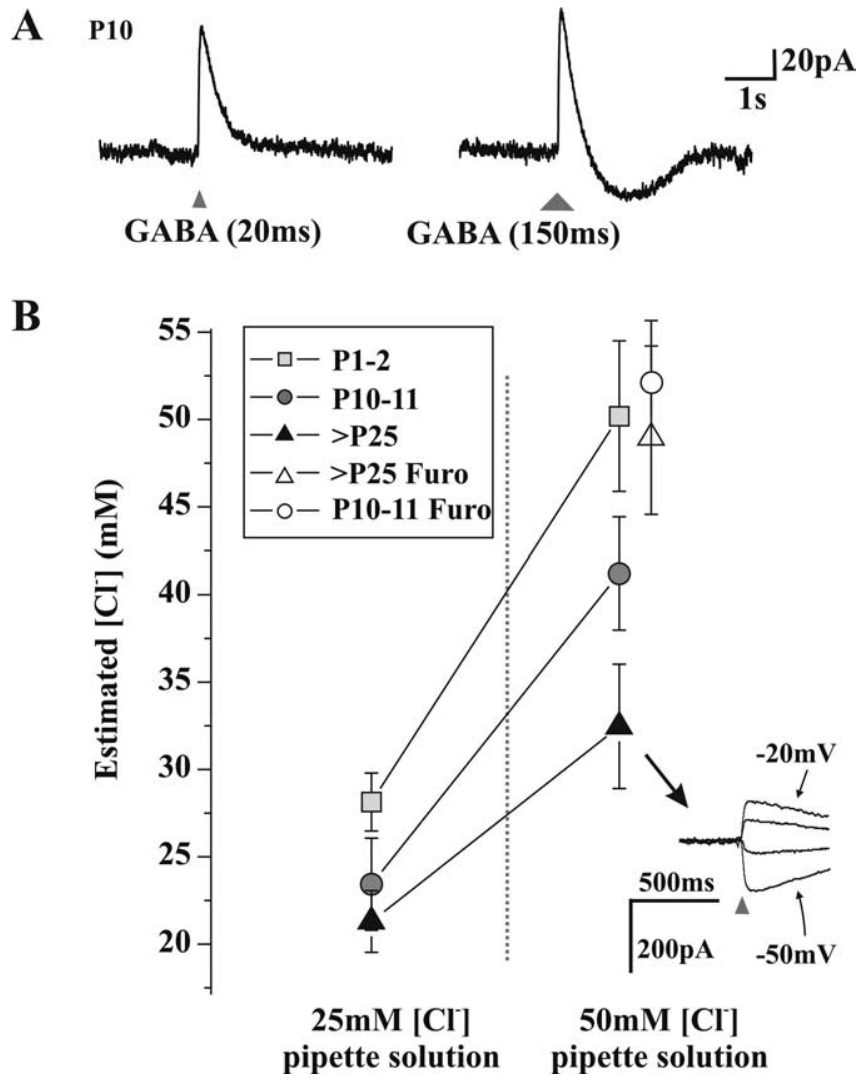

Figure 7. Measurement of $\mathrm{Cl}^{-}$extrusion capacity at different developmental stages. $A$, Voltage-clamp recordings of a neuron presenting a monophasic outward current in response to a 20 ms application of GABA (triangle, left), whereas a $150 \mathrm{~ms}$ application (larger triangle, right) produces a biphasic current response. $\boldsymbol{B}$, Estimated $\left[\mathrm{Cl}^{-}\right]_{\mathrm{i}}$ based on $E_{\text {anion }}$ measurements (see Materials and Methods) in whole-cell recorded neurons, with two high $\left[\mathrm{Cl}^{-}\right]$pipette solutions, at three developmental stages. There is a significant effect of age $(p<0.001)$ and pipette $\left[\mathrm{Cl}^{-}\right](p<0.001)$ on the resulting $\left[\mathrm{Cl}^{-}\right]_{\mathrm{i}}$ (two-way ANOVA). In the presence of the $\mathrm{KCC} 2$ antagonist furosemide (Furo), the estimated $\left[\mathrm{Cl}^{-}\right]_{i}$ of $\mathrm{P} 10-\mathrm{P} 11$ and adult neurons was not different from that of the pipette solution $(50 \mathrm{~mm})$. Inset, Example of responses to $20 \mathrm{~ms}$ applications of GABA (triangles) obtained at different holding potentials (10 mV apart) of an adult neuron with $50 \mathrm{~mm}\left[\mathrm{Cl}^{-}\right]$in the pipette.

\section{Change in net chloride extrusion capacity in developing neurons}

As outlined above, several P10-P11 neurons displayed a biphasic response to $20 \mathrm{~ms}$ GABA applications. In contrast, we did not observe biphasic responses from resting potential in adult neurons (up to P60; none of 15 cells tested) using a similar stimulus. This was consistent with the lack of $\mathrm{Ca}^{2+}$ responses in rats older than P25 (Fig. 1). However, purely outward responses could be converted to biphasic by prolonging the GABA application from 20 to $150-300 \mathrm{~ms}(n=11$ of 18$)$ (Fig. $7 A)$ at both ages. We interpreted this as suggesting that the prolonged GABA application led to an increased $\mathrm{Cl}^{-}$load, exceeding the $\mathrm{Cl}^{-}$extrusion capacity of the cell. Thus, it appeared that $\mathrm{Cl}^{-}$extrusion capacity was important in shaping the response of the neuron to GABA. These observations prompted us to conduct a quantitative assessment of $\mathrm{Cl}^{-}$extrusion capacity of LI neurons cells at different postnatal ages. To do so, we challenged the cells with a high $\mathrm{Cl}^{-}$ load in whole-cell recording configuration (Jarolimek et al., 1999; Staley and Proctor, 1999; DeFazio et al., 2000).

When $25 \mathrm{mM} \mathrm{Cl}^{-}$was included in the recording pipette solution, P1-P2, P10-P11, and adult (older than P25) neurons had, respectively, a resulting estimated intracellular $\left[\mathrm{Cl}^{-}\right]$of $27.6 \pm$ 
$1.0 \mathrm{~mm}(n=9), 22.9 \pm 1.7 \mathrm{~mm}(n=13)$, and $20.7 \pm 1.4 \mathrm{~mm}(n=$ 19) (Fig. $7 B$ ). When the pipette $\left[\mathrm{Cl}^{-}\right]$was increased to $50 \mathrm{~mm}$, the resulting estimated $\left[\mathrm{Cl}^{-}\right]_{\mathrm{i}}$ for $\mathrm{P} 1-\mathrm{P} 2, \mathrm{P} 10-\mathrm{P} 11$, and adult neurons was $50.2 \pm 4.3 \mathrm{mM}(n=7), 41.2 \pm 3.2 \mathrm{mM}(n=16)$, and $32.5 \pm 3.6 \mathrm{~mm}(n=10)$, respectively (Fig. $7 B)$. Two-way ANOVA revealed that there was a significant effect of both age $(p<0.001)$ and pipette $\left[\mathrm{Cl}^{-}\right](p<0.001)$ on the resulting $\left[\mathrm{Cl}^{-}\right]_{\mathrm{i}}$. These results clearly indicate that $\mathrm{P} 10-\mathrm{P} 11$ neurons have a $\mathrm{Cl}^{-}$extrusion capacity intermediate between $\mathrm{P} 1-\mathrm{P} 2$ neurons, in which $\left[\mathrm{Cl}^{-}\right]_{\mathrm{i}}$ essentially equals $\left[\mathrm{Cl}^{-}\right]$in the pipette, and adult neurons that were able to maintain a $\left[\mathrm{Cl}^{-}\right]_{\mathrm{i}}$ up to nearly $20 \mathrm{~mm}$ below $\left[\mathrm{Cl}^{-}\right]$in the pipette (Fig. $7 B$ ).

To test whether this was attributable to a higher $\mathrm{Cl}^{-}$extrusion capacity in adult cells, we bath applied furosemide onto the slices from rats at different ages and measured the intracellular $\left[\mathrm{Cl}^{-}\right]_{\mathrm{i}}$ with a pipette containing $50 \mathrm{~mm}\left[\mathrm{Cl}^{-}\right]$. Under these conditions, measured $\left[\mathrm{Cl}^{-}\right]_{\mathrm{i}}$ was $49.4 \pm 4.8(n=5)$ for P10-P11 cells and $52.1 \pm 3.5(n=3)$ for adult neurons, not significantly different from measured $\left[\mathrm{Cl}^{-}\right]_{\mathrm{i}}$ in P1-P2 cells without furosemide or excised patches $(51.7 \pm 3.8 ; n=6)$. Thus, furosemide produced a greater increase in $\left[\mathrm{Cl}^{-}\right]_{\mathrm{i}}$ in adult versus $\mathrm{P} 10$ cells, demonstrating that KCC2 activity increased with age.

The latter estimations of resulting $\left[\mathrm{Cl}^{-}\right]_{\mathrm{i}}$ are based on $E_{\text {anion }}$ measurements and on the assumption that intracellular and extracellular bicarbonate concentrations are constant across ages (see Materials and Methods). However, these concentrations may also change during development. Indeed, the neuronal carbonic anhydrase, which enhances the regeneration of $\mathrm{HCO}_{3}^{-}$ from $\mathrm{CO}_{2}$ in conditions in which a $\mathrm{HCO}_{3}^{-}$conductance is activated, has been shown to be developmentally regulated and expressed after P12 in the hippocampus (Ruusuvuori et al., 2004). Such developmental regulation has not been described in spinal LI neurons, but, if a similar lower carbonic anhydrase activity occurred in immature spinal neurons, it would mean that our calculations effectively underestimated $\left[\mathrm{Cl}^{-}\right]_{\mathrm{i}}$ in young animals. Thus, if anything, we underestimated the gap in extrusion capacity between immature and adult neurons.

Differences in $\mathrm{Cl}^{-}$extrusion capacity provide a mechanism for the apparent discrepancy between the occurrence of $\mathrm{GABA}_{\mathrm{A}}$ receptor-mediated rise in $\left[\mathrm{Ca}^{2+}\right]_{\mathrm{i}}$ and the evolution of resting $E_{\text {anion }}$ during development. Indeed, our results indicate that, even if neurons in the second postnatal week have a $\mathrm{Cl}^{-}$extrusion capability sufficient to yield a hyperpolarizing driving force for anions, at rest, similar to that in adults (Fig. 3), this $\mathrm{Cl}^{-}$extrusion capacity has nevertheless not reached its adult efficacy. This weaker $\mathrm{Cl}^{-}$extrusion can explain the frequent occurrence of biphasic responses to GABA and the accompanying rise in $\left[\mathrm{Ca}^{2+}\right]_{\mathrm{i}}$ observed during the second postnatal week.

\section{Discussion}

Using intracellular calcium-imaging, whole-cell, and perforatedpatch recordings and measurements of $\mathrm{Cl}^{-}$extrusion capacity in spinal LI, we demonstrate that a variety of factors affect the net outcome of $\mathrm{GABA}_{\mathrm{A}}$ receptor-mediated transmission at each stage of postnatal development. Taking into account these different factors, we find that the $\mathrm{GABA}_{\mathrm{A}}$ signaling in spinal LI reaches full maturity only by the third postnatal week.

\section{Maturation of $E_{\text {anion }}$ and chloride extrusion capacity}

Initial reports of a switch in GABA (or glycine) action during development were based on intracellular recordings (Ben Ari et al., 1989) and later confirmed using the perforated-patch technique that further minimized the interference of the pipette so- lution with the intracellular milieu (Abe et al., 1994; Kyrozis and Reichling, 1995). In our hands, despite the difference in preparation and lamina under study, we obtained a similar timeframe for the hyperpolarizing shift in reversal potential (measured at the beginning of $\mathrm{GABA}_{\mathrm{A}}$ responses) to that published previously for spinal dorsal horn neurons (Baccei and Fitzgerald, 2004). These measurements of the relative position of $E_{\text {anion }}$ and resting membrane potential indicate that, in the spinal cord, as in the hippocampus (Ben Ari et al., 1997), this developmental shift is completed within the first postnatal week.

Membrane proteins extruding and intruding $\mathrm{Cl}^{-}$are known to be developmentally regulated, causing a shift in $E_{\text {anion }}$ during development (Rivera et al., 1999; Kelsch et al., 2001). However, the precise time course of their increase in expression or activity [these two parameters appear to differ (Balakrishnan et al., 2003)] has not yet been determined in the spinal dorsal horn. Both our perforated-patch recordings and our whole-cell recordings with high pipette $\left[\mathrm{Cl}^{-}\right]$give new insights into the $\mathrm{Cl}^{-}$extrusion capacity of developing LI neurons. At P10, the $E_{\text {anion }}$ measured at the beginning of $\mathrm{GABA}_{\mathrm{A}}$ responses was found to be similar to that in adult neurons. Thus, P10 neurons appear to have a similar ability to maintain a low $\left[\mathrm{Cl}^{-}\right]$in resting conditions as adult neurons do. However, their response to a $\mathrm{Cl}^{-}$ challenge clearly differs from that of adult neurons, because (1) they cannot overcome a high $\left[\mathrm{Cl}^{-}\right]$imposed by the patch pipette and (2) they have a weaker ability to maintain their $E_{\text {anion }}$ during repetitive or bursts of GABAergic input. The observation that short bursts of activity are sufficient to cause a collapse of the $\mathrm{Cl}^{-}$ gradient indicates that this is relevant to many of the sensory inputs that the neurons may be subject to. Our results suggest that, although active $\mathrm{Cl}^{-}$extrusion occurs in P10 neurons, it has not reached its maximal, adult capacity.

\section{Mechanisms of GABA-induced rises in $\left[\mathrm{Ca}^{2+}\right]_{\mathrm{i}}$ and biphasic voltage responses}

We have chosen calcium imaging as an alternative technique to study the net effects of GABA on young LI neurons. We confirmed that it provides a complementary approach to evaluate the developmental shift in GABA action by taking into account both subthreshold and suprathreshold responses (in terms of spike generation). When its propensity for inducing a rise in $\left[\mathrm{Ca}^{2+}\right]_{\mathrm{i}}$ in LI neurons is considered, GABA reaches its adult phenotype (i.e., close to $0 \%$ of responding neurons) only by the end of the third postnatal week. Another study that indirectly measured the effect of GABA through extracellular multiple-unit and cell-attached recordings of spike frequencies in the hippocampus also gave an estimate of a later excitation-to-inhibition switch (Khazipov et al., 2004) than that expected based on intracellular recordings of $E_{\text {anion }}$ in the same neurons (Ben Ari et al., 1989). It is also interesting to note here that maturation of the mixed glycine and $\mathrm{GABA}_{\mathrm{A}}$ receptor-mediated transmission in the superficial dorsal horn also occurs over 3 weeks postnatally (Keller et al., 2001). Our results, together with these studies, confirm that monitoring only the evolution of $E_{\text {anion }}$ provides an incomplete view of the maturation of GABA action.

Simultaneous calcium imaging and patch recordings revealed that a pure depolarization at the onset of the response to GABA was not the only voltage response associated with an increase in $\left[\mathrm{Ca}^{2+}\right]_{\mathrm{i}}$. Biphasic responses could also be accompanied by a rise in $\left[\mathrm{Ca}^{2+}\right]_{\mathrm{i}}$, therefore reconciling the apparent mismatch between $E_{\text {anion }}$ and the effect of GABA on $\left[\mathrm{Ca}^{2+}\right]_{\mathrm{i}}$. The involvement of biphasic responses was interesting in that the depolarization follows a hyperpolarization, a situation that is ideal for the gating of 
low-voltage-activated calcium channels, such as the T-type, consistent with our finding that they are implicated in the GABAinduced rise in $\left[\mathrm{Ca}^{2+}\right]_{\mathrm{i}}$.

Our results suggest that the $\mathrm{GABA}_{\mathrm{A}}$ receptor-mediated biphasic responses observed in immature LI neurons are mainly attributable to an intracellular $\mathrm{Cl}^{-}$accumulation. There are several reasons for this. First, an analysis of the evolution of the membrane conductance during the response shows that there is no depolarization outlasting the opening of $\mathrm{GABA}_{\mathrm{A}}$ channels. Second, repeated applications of GABA clearly caused a more prolonged change in conductance and $E_{\mathrm{GABA}}$ than that reported in other systems (Kaila et al., 1997; Perkins, 1999). Third, both calcium responses and biphasic patch responses were observed in TTX, precluding the involvement of activity-dependent, network-driven processes. Finally, our experiments clearly demonstrate that P10 neurons do not demonstrate a fully functional $\mathrm{Cl}^{-}$extrusion capacity, therefore providing a mechanism for $\mathrm{Cl}^{-}$ accumulation during $\mathrm{GABA}_{\mathrm{A}}$ responses. The balance between reversal potential, $\mathrm{Cl}^{-}$extrusion capacity, and intensity of the $\mathrm{Cl}^{-}$challenge appears subtle, and a modification of any of these parameters is susceptible to affect the type of GABA response observed.

A recent study described an interesting novel mechanism for the coupling of $\mathrm{GABA}_{\mathrm{A}}$-mediated transmission to rises in $\left[\mathrm{Ca}^{2+}\right]_{\mathrm{i}}$ in cerebellar granule cells (Chavas et al., 2004). It involves a change in osmotic tension attributable to intracellular $\mathrm{Cl}^{-}$accumulation. Such a mechanism could be partially involved in the responses described in our study. However, the mechanism described by Chavas et al. (2004) appears to occur at a different timescale than the responses described here and does not appear to be developmentally regulated. Furthermore, our calcium responses show very rapid onset, matching that of the depolarization, remain in absence of $\mathrm{Cl}^{-}$influx (see response at hyperpolarized potentials in Fig. $4 \mathrm{~B}$ ), and are attenuated by blockers of VGCCs. Thus, a prominent component of the $\mathrm{GABA}_{\mathrm{A}}$-mediated rises in $\left[\mathrm{Ca}^{2+}\right]_{\mathrm{i}}$ in our study involves a membrane depolarization.

\section{Functional significance}

Calcium imaging gives insight into a functional role for GABA during development. First, $\mathrm{GABA}_{\mathrm{A}}$ receptor-mediated rises in $\left[\mathrm{Ca}^{2+}\right]_{\mathrm{i}}$ and the downstream activation of intracellular cascades have been demonstrated, or suggested, to underlie the trophiclike properties of GABA on proliferation, cell migration, and differentiation (Owens and Kriegstein, 2002; Fiszman and Schousboe, 2004). Because the GABA-induced rise in $\left[\mathrm{Ca}^{2+}\right]_{i}$ can be observed in some neurons until the end of the third postnatal week in LI neurons, it is conceivable that GABA still exerts such trophic properties on a subset of neurons at that age.

Another proposed role for GABA early in development arises from the observation that, at that moment, glutamatergic synapses are "silent" at rest because they lack AMPA receptors and NMDA channels are blocked by $\mathrm{Mg}^{2+}$ (Li and Zhuo, 1998). At that stage, $\mathrm{GABA}_{\mathrm{A}}$ receptors can play the role of a gating mechanism, by which depolarization of the membrane relieves the $\mathrm{Mg}^{2+}$ block from NMDA channels. Therefore, GABA has been proposed to play a crucial role in synaptic plasticity at early developmental stages and in the maturation of neuronal networks (Ben Ari et al., 1997).

We chose to record from spinal LI, because it constitutes one of the main pathways for the relay of nociceptive information from the periphery to the brain (Perl, 1984; Willis, 1989; Light, 1992; Craig, 2003). The implication of VGCCs in the GABAinduced rise in $\left[\mathrm{Ca}^{2+}\right]_{\mathrm{i}}$ strongly indicated that the membrane was effectively depolarized during the response to GABA. GABAinduced depolarization may be insufficient (or too slow) to trigger action potentials; it remains, however, that the hyperpolarizing action of GABA is lost. A simple depolarizing shift in $E_{\text {anion }}$ will not alter the membrane shunt produced by $\mathrm{GABA}_{\mathrm{A}}$ receptor opening, but inhibition involves both a shunt and a hyperpolarization of the membrane. Thus, even if the shunt remains the same, because some of the hyperpolarizing action of opening $\mathrm{Cl}^{-}$ channels is lost, a net decrease in inhibition results. A low $\mathrm{Cl}^{-}$ extrusion capacity is another potential cause of disinhibition: hyperpolarization collapses during repetitive inhibitory synaptic input. Because such disinhibitions will raise the excitability of the cells (Coull et al., 2003), it is likely that the immature phenotype of GABA on LI neurons during the second and third postnatal week is one of the substrates of the lower threshold for nociceptive withdrawal at immature stages.

The $\mathrm{Cl}^{-}$extrusion activity of dorsal horn neurons has been shown recently to play a crucial role in the development of neuropathic pain in adult rats. Indeed, blockade or knock-down of the potassium-chloride cotransporter KCC2 in the spinal cord is sufficient to dramatically reduce the nociceptive withdrawal threshold in intact rats (Coull et al., 2003). Moreover, the latter study shows that nerve injury-induced hypersensitivity is associated with a decreased expression of KCC2 in the dorsal horn. Finally, in both nerve-injured rats and after blockade of KCC2 in control adult animals, GABA caused a rise in $\left[\mathrm{Ca}^{2+}\right]_{\mathrm{i}}$ in a significant subset of LI neurons (Coull et al., 2003). This confirms that a reduced $\mathrm{Cl}^{-}$extrusion capacity of spinal LI neurons can be a cause of reduced nociceptive threshold observed in behavioral testing.

The main finding of this work is that, when diverse aspects of GABA function are under study, the maturation profile of GABA action in the spinal cord closely matches that of nociceptive threshold. This observation interestingly reconciles the maturation of spinal inhibition with the observed behavioral hyperexcitability and therefore provides a possible substrate for the lower threshold for nociceptive withdrawal at immature stages.

\section{References}

Abe Y, Furukawa K, Itoyama Y, Akaike N (1994) Glycine response in acutely dissociated ventromedial hypothalamic neuron of the rat: new approach with gramicidin perforated patch-clamp technique. J Neurophysiol 72:1530-1537.

Baccei ML, Fitzgerald M (2004) Development of GABAergic and glycinergic transmission in the neonatal rat dorsal horn. J Neurosci 24:4749-4757.

Balakrishnan V, Becker M, Lohrke S, Nothwang HG, Guresir E, Friauf E (2003) Expression and function of chloride transporters during development of inhibitory neurotransmission in the auditory brainstem. J Neurosci 23:4134-4145.

Bao J, Li JJ, Perl ER (1998) Differences in $\mathrm{Ca}^{2+}$ channels governing generation of miniature and evoked excitatory synaptic currents in spinal laminae I and II. J Neurosci 18:8740-8750.

Ben Ari Y (2002) Excitatory actions of GABA during development: the nature of the nurture. Nat Rev Neurosci 3:728-739.

Ben Ari Y, Cherubini E, Corradetti R, Gaiarsa JL (1989) Giant synaptic potentials in immature rat CA3 hippocampal neurones. J Physiol (Lond) 416:303-325.

Ben Ari Y, Khazipov R, Leinekugel X, Caillard O, Gaiarsa JL (1997) GABA NMDA and AMPA receptors: a developmentally regulated "menage a trois." Trends Neurosci 20:523-529.

Chavas J, Forero ME, Collin T, Llano I, Marty A (2004) Osmotic tension as a possible link between $\mathrm{GABA}(\mathrm{A})$ receptor activation and intracellular calcium elevation. Neuron 44:701-713.

Chery N, De Koninck Y (1999) Junctional versus extrajunctional glycine and $\mathrm{GABA}_{\mathrm{A}}$ receptor-mediated IPSCs in identified lamina I neurons of the adult rat spinal cord. J Neurosci 19:7342-7355. 
Coull JA, Boudreau D, Bachand K, Prescott SA, Nault F, Sik A, De Koninck P, De Koninck Y (2003) Trans-synaptic shift in anion gradient in spinal lamina I neurons as a mechanism of neuropathic pain. Nature 424:938-942.

Craig AD (2003) Pain mechanisms: labeled lines versus convergence in central processing. Annu Rev Neurosci 26:1-30.

De Koninck Y, Henry JL (1991) Substance P-mediated slow excitatory postsynaptic potential elicited in dorsal horn neurons in vivo by noxious stimulation. Proc Natl Acad Sci USA 88:11344-11348.

De Koninck Y, Henry JL (1994) Prolonged GABAA-mediated inhibition following single hair afferent input to single spinal dorsal horn neurones in cats. J Physiol (Lond) 476:89-100.

De Koninck Y, Ribeiro-da-Silva A, Henry JL, Cuello AC (1992) Spinal neurons exhibiting a specific nociceptive response receive abundant substance P-containing synaptic contacts. Proc Natl Acad Sci USA 89:5073-5077.

DeFazio RA, Keros S, Quick MW, Hablitz JJ (2000) Potassium-coupled chloride cotransport controls intracellular chloride in rat neocortical pyramidal neurons. J Neurosci 20:8069-8076.

Eilers J, Plant TD, Marandi N, Konnerth A (2001) GABA-mediated Ca ${ }^{2+}$ signalling in developing rat cerebellar Purkinje neurones. J Physiol (Lond) 536:429-437.

Falcon M, Guendellman D, Stolberg A, Frenk H, Urca G (1996) Development of thermal nociception in rats. Pain 67:203-208.

Fiszman ML, Schousboe A (2004) Role of calcium and kinases on the neurotrophic effect induced by gamma-aminobutyric acid. J Neurosci Res 76:435-441.

Fitzgerald M (1985) The post-natal development of cutaneous afferent fibre input and receptive field organization in the rat dorsal horn. J Physiol (Lond) 364:1-18.

Fitzgerald M (1987) Cutaneous primary afferent properties in the hind limb of the neonatal rat. J Physiol (Lond) 383:79-92.

Fitzgerald M, Gibson S (1984) The postnatal physiological and neurochemical development of peripheral sensory C fibres. Neuroscience 13:933-944.

Game CJ, Lodge D (1975) The pharmacology of the inhibition of dorsal horn neurones by impulses in myelinated cutaneous afferents in the cat. Exp Brain Res 23:75-84.

Gomora JC, Daud AN, Weiergraber M, Perez-Reyes E (2001) Block of cloned human T-type calcium channels by succinimide antiepileptic drugs. Mol Pharmacol 60:1121-1132.

Heinke B, Balzer E, Sandkuhler J (2004) Pre- and postsynaptic contributions of voltage-dependent $\mathrm{Ca}^{2+}$ channels to nociceptive transmission in rat spinal lamina I neurons. Eur J Neurosci 19:103-111.

Ikeda H, Heinke B, Ruscheweyh R, Sandkuhler J (2003) Synaptic plasticity in spinal lamina I projection neurons that mediate hyperalgesia. Science 299:1237-1240.

Jarolimek W, Lewen A, Misgeld U (1999) A furosemide-sensitive $\mathrm{K}^{+}-\mathrm{Cl}^{-}$ cotransporter counteracts intracellular $\mathrm{Cl}^{-}$accumulation and depletion in cultured rat midbrain neurons. J Neurosci 19:4695-4704.

Jiang MC, Gebhart GF (1998) Development of mustard oil-induced hyperalgesia in rats. Pain 77:305-313.

Jones SW, Marks TN (1989) Calcium currents in bullfrog sympathetic neurons. I. Activation kinetics and pharmacology. J Gen Physiol 94:151-167.

Kaila K (1994) Ionic basis of GABAA receptor channel function in the nervous system. Prog Neurobiol 42:489-537.

Kaila K, Lamsa K, Smirnov S, Taira T, Voipio J (1997) Long-lasting GABAmediated depolarization evoked by high-frequency stimulation in pyramidal neurons of rat hippocampal slice is attributable to a networkdriven, bicarbonate-dependent $\mathrm{K}^{+}$transient. J Neurosci 17:7662-7672.

Keller AF, Coull JA, Chery N, Poisbeau P, De Koninck Y (2001) Regionspecific developmental specialization of GABA-glycine cosynapses in laminas I-II of the rat spinal dorsal horn. J Neurosci 21:7871-7880.

Kelsch W, Hormuzdi S, Straube E, Lewen A, Monyer H, Misgeld U (2001) Insulin-like growth factor 1 and a cytosolic tyrosine kinase activate chloride outward transport during maturation of hippocampal neurons. J Neurosci 21:8339-8347.

Khazipov R, Khalilov I, Tyzio R, Morozova E, Ben Ari Y, Holmes GL (2004) Developmental changes in GABAergic actions and seizure susceptibility in the rat hippocampus. Eur J Neurosci 19:590-600.

Kulik A, Nishimaru H, Ballanyi K (2000) Role of bicarbonate and chloride in GABA- and glycine-induced depolarization and $\left[\mathrm{Ca}^{2+}\right]_{\mathrm{i}}$ rise in fetal motoneurons in situ. J Neurosci 20:7905-7913.

Kyrozis A, Reichling DB (1995) Perforated-patch recording with gramicidin avoids artifactual changes in intracellular chloride concentration. J Neurosci Methods 57:27-35.

Leinekugel X, Tseeb V, Ben Ari Y, Bregestovski P (1995) Synaptic GABAA activation induces $\mathrm{Ca}^{2+}$ rise in pyramidal cells and interneurons from rat neonatal hippocampal slices. J Physiol (Lond) 487:319-329.

Li P, Zhuo M (1998) Silent glutamatergic synapses and nociception in mammalian spinal cord. Nature 393:695-698.

Light AR (1992) The initial processing of pain and its descending control: spinal and trigeminal systems. Basel: Karger.

Lima D, Coimbra A (1988) The spinothalamic system of the rat: structural types of retrogradely labelled neurons in the marginal zone (lamina I). Neuroscience 27:215-230.

Lin MH, Takahashi MP, Takahashi Y, Tsumoto T (1994) Intracellular calcium increase induced by GABA in visual cortex of fetal and neonatal rats and its disappearance with development. Neurosci Res 20:85-94.

Magistretti J, Ragsdale DS, Alonso A (1999) High conductance sustained single-channel activity responsible for the low-threshold persistent $\mathrm{Na}^{+}$ current in entorhinal cortex neurons. J Neurosci 19:7334-7341.

Marsh D, Dickenson A, Hatch D, Fitzgerald M (1999) Epidural opioid analgesia in infant rats I: mechanical and heat responses. Pain 82:23-32.

Owens DF, Kriegstein AR (2002) Is there more to GABA than synaptic inhibition? Nat Rev Neurosci 3:715-727.

Owens DF, Boyce LH, Davis MB, Kriegstein AR (1996) Excitatory GABA responses in embryonic and neonatal cortical slices demonstrated by gramicidin perforated-patch recordings and calcium imaging. J Neurosci 16:6414-6423.

Perkins KL (1999) $\mathrm{Cl}^{-}$accumulation does not account for the depolarizing phase of the synaptic GABA response in hippocampal pyramidal cells. J Neurophysiol 82:768-777.

Perl ER (1984) Pain and nociception. In: Sensory processes (Darian-Smith I, ed), pp 915-975. Bethesda: American Physiological Society.

Reichling DB, Kyrozis A, Wang J, MacDermott AB (1994) Mechanisms of GABA and glycine depolarization-induced calcium transients in rat dorsal horn neurons. J Physiol (Lond) 476:411-421.

Rivera C, Voipio J, Payne JA, Ruusuvuori E, Lahtinen H, Lamsa K, Pirvola U, Saarma M, Kaila K (1999) The $\mathrm{K}^{+} / \mathrm{Cl}^{-}$co-transporter KCC2 renders GABA hyperpolarizing during neuronal maturation. Nature 397:251-255.

Ruusuvuori E, Li H, Huttu K, Palva JM, Smirnov S, Rivera C, Kaila K, Voipio J (2004) Carbonic anhydrase isoform VII acts as a molecular switch in the development of synchronous gamma-frequency firing of hippocampal CA1 pyramidal cells. J Neurosci 24:2699-2707.

Ryu PD, Randic M (1990) Low- and high-voltage-activated calcium currents in rat spinal dorsal horn neurons. J Neurophysiol 63:273-285.

Schwark HD, Tennison CF, Ilyinsky OB, Fuchs JL (1999) Inhibitory influences on receptive field size in the dorsal column nuclei. Exp Brain Res 126:439-442.

Shmigol A, Kostyuk P, Verkhratsky A (1994) Role of caffeine-sensitive $\mathrm{Ca}^{2+}$ stores in $\mathrm{Ca}^{2+}$ signal termination in adult mouse DRG neurones. NeuroReport 5:2073-2076.

Smirnov S, Paalasmaa P, Uusisaari M, Voipio J, Kaila K (1999) Pharmacological isolation of the synaptic and nonsynaptic components of the GABA-mediated biphasic response in rat CAl hippocampal pyramidal cells. J Neurosci 19:9252-9260.

Sorkin LS, Puig S, Jones DL (1998) Spinal bicuculline produces hypersensitivity of dorsal horn neurons: effects of excitatory amino acid antagonists. Pain 77:181-190.

Staley KJ, Proctor WR (1999) Modulation of mammalian dendritic GABA(A) receptor function by the kinetics of $\mathrm{Cl}^{-}$and $\mathrm{HCO}^{-}$transport. J Physiol (Lond) 519:693-712.

Staley KJ, Soldo BL, Proctor WR (1995) Ionic mechanisms of neuronal excitation by inhibitory GABAA receptors. Science 269:977-981.

Talley EM, Cribbs LL, Lee JH, Daud A, Perez-Reyes E, Bayliss DA (1999) Differential distribution of three members of a gene family encoding low voltage-activated (T-type) calcium channels. J Neurosci 19:1895-1911.

Teng CJ, Abbott FV (1998) The formalin test: a dose-response analysis at three developmental stages. Pain 76:337-347.

Thastrup O, Cullen PJ, Drobak BK, Hanley MR, Dawson AP (1990) Thapsigargin, a tumor promoter, discharges intracellular $\mathrm{Ca}^{2+}$ stores by spe- 
cific inhibition of the endoplasmic reticulum $\mathrm{Ca}^{2+}$-ATPase. Proc Natl Acad Sci USA 87:2466-2470.

Tyzio R, Ivanov A, Bernard C, Holmes GL, Ben Ari Y, Khazipov R (2003) Membrane potential of CA3 hippocampal pyramidal cells during postnatal development. J Neurophysiol 90:2964-2972.

Wang C, Ohno K, Furukawa T, Ueki T, Ikeda M, Fukuda A, Sato K (2005) Differential expression of KCC2 accounts for the differential GABA responses between relay and intrinsic neurons in the early postnatal rat olfactory bulb. Eur J Neurosci 21:1449-1455.

Wang J, Reichling DB, Kyrozis A, MacDermott AB (1994) Developmental loss of GABA-induced and glycine-induced depolarization and $\mathrm{Ca}^{2+}$ transients in embryonic rat dorsal horn neurons in culture. Eur J Neurosci 6:1275-1280.

Westenbroek RE, Hoskins L, Catterall WA (1998) Localization of $\mathrm{Ca}^{2+}$ channel subtypes on rat spinal motor neurons, interneurons, and nerve terminals. J Neurosci 18:6319-6330.

Whyte KA, Greenfield SA (2002) Expression of voltage-dependent calcium channels in the embryonic rat midbrain. Brain Res Dev Brain Res 139:189-197.

Willis WD (1989) The origin and destination of pathways involved in pain transmission. In: Textbook of pain (Wall PD, Melzack R, eds), pp 112127. New York: Churchill Livingstone.

Yamada J, Okabe A, Toyoda H, Kilb W, Luhmann HJ, Fukuda A (2004) $\mathrm{Cl}^{-}$ uptake promoting depolarizing GABA actions in immature rat neocortical neurones is mediated by NKCC1. J Physiol (Lond) 557:829-841.

Yuste R, Katz LC (1991) Control of postsynaptic $\mathrm{Ca}^{2+}$ influx in developing neocortex by excitatory and inhibitory neurotransmitters. Neuron 6:333344. 